to phenylbutazone and related compounds, sulfadiazine, and sulfisoxazole. Patients with an active peptic ulcer should not be given sulphinpyrazone. Finally it should be publicised that blood dyscrasias have been reported to be due to this drug, although rarely.

I hope these comments will heighten the clinical awareness of the side effects of sulphinpyrazone.

SAEed AhMad

Fairmont General Hospital,

Fest Virginia, USA

\section{Tuberculin testing}

SIR,-I refer to the note on tuberculin testing (13 January, p 108), in which reference is again made to the unreliability of the tine tuberculin test. The only alternative mentioned is the Mantoux test. This calls for accurate intracutaneous injection of the tuberculin. I find that young doctors have not been trained in this technique and do not trust themselves (nor are trusted by their seniors) to perform the test satisfactorily.

This causes me to ask what has become of the Heaf test. I used it with complete confidence for many years and advised its use throughout Northern Ireland in connection with the BCG vaccination programme of the Northern Ireland Tuberculosis Authority. The Heaf gun demands no special skill in its operation. Has it already been discarded as an obsolete instrument ?

H G Calwell

Carrickfergus,

Co Antrim

\section{Nice people with no manners}

SIR,_- "Nice people with no manners" by Dr Stephen Lock (23 December, p 1774) aptly portrays problems which can slightly mar an enjoyable evening for the speaker. These are, as he shows, not confined to our profession. Indeed Stephen .Leacock, humorist and academician, wrote an essay on "How it feels to be a lecturer." $\mathrm{He}$ wittily described experiences he had when touring England and elsewhere: chairman had forgotten his name or got it wrong and one had to read out the subject of his talk from the programme. He wrote that "the first of the troubles ... is the fact that the audience will not come to hear him." Research could be done on what inspires doctors to attend meetings: how important is the subject, the speaker-or perhaps the meal ? Some years ago as secretary to a medical society I got a speaker who had filled a vast hall in New York. Here the usual audience of about 19 attended. Shortly afterwards I invited an expert on income tax for doctors: the place was packed.

Most speakers could vie with each other in telling depressing tales-for example, an audience hardly more numerous than the speakers who had travelled many miles through snow and ice on a Sunday. Another time, after being surrounded by about 200 people when being given sustenance just before the lecture, as the time approached the crowd faded away leaving a handful of people, as the lecture had coincided with the hospital ball. Nevertheless, it was a pleasant evening, as the audience was one of quality rather than quantity.

Fortunately, the nice people with no manners are, in my experience as well, rare. Usually the clearest details are given about the time, place, duration of talk, and type of audience-and hospitality is generous. The commonest difficulties are technical, particularly when showing slides. Some problems are avoidable, such as having a spare bulb, spare projector, and someone who understands the machine. Others are unpredictable, such as poor attendance or a power cut.

Clifford Hawkins

Queen Elizabeth Hospital, Birmingham

Haemodynamic effects of buprenorphine after heart surgery

SIR,-It is impossible to find justification in the article by Dr F L Rosenfeldt and others (9 December, $p$ 1602) for their conclusion that "Buprenorphine appears to be safer than morphine for use in patients with reduced cardiac reserve. ..."

No evidence is presented by the authors to suggest that their patients, studied after open heart surgery, were in an unstable cardiovascular state or had a reduced cardiac reserve and the effects of morphine were not studied. The finding of a $24 \mathrm{mmHg}$ fall in the mean arterial pressure in $18^{\circ} \%$ of the patients studied suggests that the hypotensive effect of intravenous buprenorphine may be clinically relevant. The subsequent statement by the authors that "there was no overall change in mean arterial pressure" cannot be evaluated as no relevant data are provided.

One must conclude that buprenorphine may cause a fall in arterial blood pressure in some patients and that there is no justification on the evidence presented in the study for considering it to be safer than morphine as an intravenous analgesic.

D W BETHUNE

Thoracic Surgical Unit,

Papworth Hospital

Cambridge

${ }_{*}^{*}$ We sent a copy of this letter to the authors, whose reply is printed below.-ED, $B M \mathcal{H}$.

SIR,-Thank you for allowing us to reply to the important issues raised by Dr Bethune.

The purpose of this paper was to report the haemodynamic effects of buprenorphine after cardiac surgery. In keeping with the style of the $B M f$ we trimmed our paper in many directions and are therefore delighted for the opportunity of supplying further information to $\mathrm{Dr}$ Bethune. $\mathrm{He}$ may judge from our previous publications on a similar group of patients ${ }^{12}$ that these patients do indeed have an unstable cardiovascular system. This is well recognised by most workers in the immediate period following open heart surgery, when such patients have to be treated in an intensive care unit to monitor closely the circulatory state.

Regarding Dr Bethune's query about the fall in arterial pressure, table printed below shows the change in mean arterial pressure, cardiac output, and heart rate, justifying our statement that "there was no overall change in mean arterial pressure."

We carefully referred to our review of the haemodynamic effects of other analgesic agents $^{3}$ and we have directly compared buprenorphine with Omnopon in the same patients, using the protocol we outlined in our paper. Considering the known haemodynamic effects of morphine in such patients we firmly believe that our conclusions are justified.

D J COLTART

D THOMPSON

N NAQUI

Department of Cardiology,

St Thomas's Hospital

1 Lewis, G J R, et al, European fournal of Cardiology, $1978,7,283$.

Lewis, G J R, et al, American Heart fournal, 1978, 95,

Malcolm, A D, and Coltart, D J, in Pain-New Perspectives in Measurement and Management, ed A W Harcus, R B Smith, and B A Whit

\section{Normality and abnormality in} psychiatry

SIR,-The letter of Dr J G Edwards (4 November, p 1296) is a timely reminder of the problems of delineating normality in psychiatric practice. Indeed, it has been cynically noted in a university students' publication that those who are normal are "other people a psychiatrist has never met."1 That there may be an element of truth in this is attested to by the fact that "homoclite" was coined to indicate a mentally healthy young man. ${ }^{2}$ Furthermore, it has been suggested that those persons who claim to be free of any psychological symptoms may only be unusually capable of concealing their symptoms. $^{3}$

"Normality and the psychiatrist" was the subject of a recent Australian paper. ${ }^{4}$ In addition to the statistical, clinical, and prognostic aspects referred to by Professor Geoffrey Rose and Dr D J P Barker (23 September, p 873) and the sociocultural component noted by Dr Edwards, this alluded to the fact that a Utopian ideal of health is sometimes regarded as normal and to the differing standards of normality taken in a developmental sense.

There is no doubt that normality must be considered according to many parameters, and one can only endorse Dr Edwards's comments that it is most important for doctors to recall that the designation of abnormality has farreaching implications. For the individual it may involve expensive and uncomfortable investigations, isolation from the community, and uncertainty for the future. For society, it offers a means of categorising an individual.

Haemodynamic response in eight patients followed for 60 minutes after administration of buprenorphine Values are mean $\pm 1 S E M$

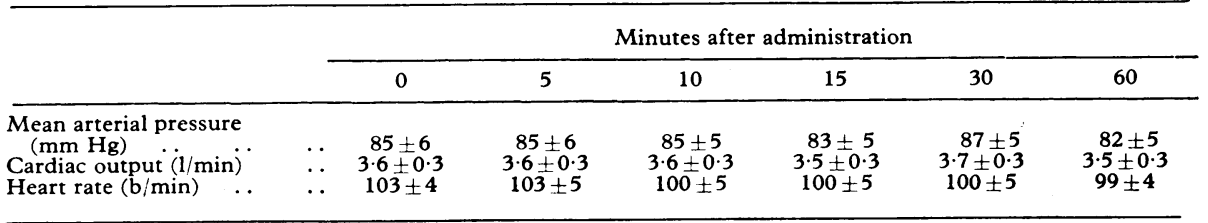


which may well be detrimental to that person's overall well-being.

Department of Psychiatry,

University of Adelaide,

South Australia

'National $U$ (Canberra), 30 April, 1975.

Grinker, R R, et al, Archives of General Psychiatry,

1962, 6, 405.
Eissler, K R, in The Psychoanalytic Study of Society, IUP, 1960

4oldney, R D, Australian and New Zealand fournal of
Psychiatry, 1974, 8, 199.

\section{Shingles: a belt of roses from Hell}

SIR,-Your leading article on shingles (6 January, p 5) gives an excellent account of the pathology, clinical picture, and early treatmen of this common disease. Unfortunately there are many patients who continue to have severe, long-term discomfort and I believe there is much more to offer than "analgesics, sympathy, and a liberal helping of hope." For example, in pain relief clinics throughout the country many of these individuals have been helped, though seldom completely relieved, by transcutaneous nerve stimulation and similar methods of recruitment of large-fibre paininhibitory systems..$^{2}$ It is disappointing also to find no reference to drug regimens incorporating anticonvulsants with tricyclic antidepressants. There is much clinical evidence to support the use of fluphenazine with amitriptyline ${ }^{3}$ and sodium valproate with amitriptyline. ${ }^{4}$ Peripheral nerve blocks are of limited value except for those with superficial burning dysaesthesia.

Pain Relief Unit,

Norfolk and Norwich Hospital,

Norwich

${ }^{1}$ Nathan, P W, and Wall, P D, British Medical fournal, $1974,3,645$.

Mehta, M, Anaesthesia, 1978, 33, 258.

Taub, A, and Collins, W F, in Advances in Neurology, vol 4, ed J Bonica, p 309. New York, Raven Press, 1974.

Raftery, H, communication to Second World Congress on pain, Montreal, September 1978.

SIR,-Despite much interesting information about herpes zoster in your leading article (6 January, p 5), some of your statements must not go unchallenged. It is our contention that there is no reliable information suggesting that treatment of zoster with systemic steroids causes dissemination of the disease except in the immunosuppressed patient. Such immunosuppression does not occur during a short course of steroid therapy. But let us assume that dissemination does occur, and what do we have-chickenpox. Disseminated zoster is potentially lethal only in the immunosuppressed. It is interesting that, of the references quoted, No 20 , an article by Juel-Jensen, ${ }^{1}$ quotes as the main evidence for the dangers of dissemination of steroid-treated zoster a notoriously bad article by Merselis et al. This was reviewed in the Year Book of Dermatology, ${ }^{2}$ with the comment that "Avoidance of corticosteroids ... is not justified on the basis of the material presented.... It should be mentioned that systemic steroids are now an accepted approach to the treatment of herpes zoster, especially when ophthalmic involvement is a feature." Indeed, you state that early treatment with systemic steroids reduces the incidence of postherpetic neuralgia.

Now to the question of cost. Even if 33\% idoxuridine were available in general practice, its cost to this hospital is $£ 102$ for $30 \mathrm{ml}$. Although we have not yet decided how this could be applied "constantly to the whole dermatome for four days" (a continuous recycling spray inside an oxygen tent ?), the cost-since $\mathrm{C} 4$, for example, has a rough surface area of $258 \mathrm{~cm}^{2}$-would run to possibly $£ 1000$ or more per patient.

This department, with its general practitioner assistants, has treated many hundreds of cases of zoster with prednisolone over 20 years and with excellent therapeutic effect, and will continue to do so-at a rough cost of less than $100 \mathrm{p}$ per patient.

K D CROW

Julia P Ellis

Princess Margaret Hospital

Swindon, Wilts

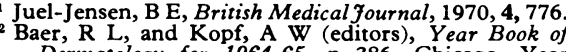
Dermatology for 1964-65, p 386. Chicago, Year

\section{Computers and confidentiality}

SIR,-Your leading article "Computers and confidentiality" (16 December, p 1663) criticises the Report of the Committee on Data Protection (HMSO Cmnd 7341) for its failure to ensure the inviolability of the doctor's "right" to keep his records from his patients. Had you explained our proposals even briefly your readers might have been able to judge for themselves whether our conclusions were unreasonable.

We suggested that the Act should lay down the duties of a data protection authority (DPA) and the principles by which it should be guided. But our witnesses made it clear that a single set of rules built into the statute would lead to unnecessary costs being placed on the users of personal data whose activities posed little threat to privacy, and we knew that changes taking place in computer hardware might rapidly outdate the provisions of a statute. To meet these and other problems we proposed that the DPA should prepare subsidiary legislation in the form of codes of practice for different applications, including codes for medical records, for medical research, for social service records, and so on. We envisaged that about 50 codes would be needed for all applications. We specifically urged that the codes should be worked out bilaterally between the DPA and representatives of the users, a point you unfortunately missed. The medical profession would thus have a full voice in determining whether patients should have the right of access to their files (and, at the moment, this refers only to computer files). The weight of the arguments presented by our witnesses was against right of access, so we accepted that the code for medical records should stipulate an exemption from the general rule that a data subject should be able to see his record. It should be clear that an exception to the general rule was being made for medical records. But should there ever be public pressure to remove this exception the profession would be able to play a part in determining the outcome through their consultations with the DPA.

Your suggestion that this exception be in the statute is contrary to the whole philosophy of the report. It is extremely cumbersome to change an Act, whereas the codes of practice, as subsidiary legislation, could be relatively easily altered as circumstances changed. If at some later date the consensus were that patients should have the right of access, there would be few procedural obstacles to overcome.

The advantages to medicine of a Data Protection Act should be substantial. You mention the success of the Oxford Record Linkage Study, without explaining that some doctors refuse to co-operate with it because they cannot in good conscience supply identifiable medical data to a computer system which is not regulated by law. If the system were regulated, the Aylesbury doctors would probably lift their ban. This could equally apply to other computer projects in the health field which have run into trouble because of lack of firm safeguards. Thus, rather than stultifying computer developments in medicine, the Data Protection Act should remove much of the basis for opposition and apprehension.

Charles Florey

Department of Community Medicine,
St Thomas's Hospital Medical School
London SE1

\section{Safety in clinical laboratories}

SIR,-It has recently been claimed by Mr D C Jenkins, general secretary of the Association of Scientific, Technical and Managerial Staffs, that no action has been taken for more than three years to improve the standards of safety in NHS laboratories. ${ }^{1}$ It was also implied that Crown immunity of such Government-controlled departments has been used as a means of avoiding the institution of improvements.

The facts are that there has been a great deal of activity in the study and publicising of laboratory hazards, highlighted by the Howie Report and by your leading article on it (8 April 1978, p 871). Despite financial stringency definite improvements have been made, particularly in relation to hepatitis, the annual incidence of which in 1975-6 fell to only one-quarter of what it was in 1970-4. There is still room for improvement in the prevention of infection, especially in relation to tuberculosis in post-mortem room staff; but the potential for major disaster in recent years has arisen in laboratories outside the NHS.

The control of non-infective hazardschemical poisons, radioactivity, fire, explosion, electrical dangers, noise, and faulty centrifuges -is improving: for example, in relation to radioisotopes there are stringent regulations which are enforced as much in Crown establishments as elsewhere.

Finally, it is surprising to us that $\mathrm{Mr}$ Jenkins is apparently unaware of all these activities designed to improve the safety of his members in NHS laboratories, in which his members are active participants and have contributed to the drawing up of safety codes which have been used for some years in hospital laboratories. The emotions raised by the recent occurrence in Birmingham are understandable, but outbursts unrelated to the facts do not help.

Heather M Dick onvener of Association of Clinical
Pathologists' Working Party on Safety in Laboratories
L

Department of Bacteriology,

Royal Infirmary,
Glasgow

Loshak, D, Sunday Telegraph, 7 January, 1979.
2 Grist, N R, fournal of Clinical Pathology, 1978, 31, 